\title{
Perioperative use of transesophageal echocardiog- raphy by anesthesiologists: impact in noncardiac surgery and in the intensive care unit
}

\author{
[L'utilisation périopératoire de l'échocardiographie transosophagienne par les anesthésio- \\ logistes : les répercussions en chirurgie non cardiaque et à l'unité des soins intensifs]
}

André Y. Denault MD FRCPC, * Pierre Couture MD FRCPC, ${ }^{*}$ Sylvie McKenty MD FrCPC, $†$ Daniel Boudreault MD FrCPC, $\dagger$ François Plante MD FRCPC, $\dagger$ Roger Perron RRT, $†$ Denis Babin MSc, ${ }^{*}$ Jean Buithieu MD FRCPC $\ddagger$

Background: The American Society of Anesthesiologists (ASA) has published practice guidelines for the use of perioperative transesophageal echocardiography (TEE) but the role and impact of TEE performed by anesthesiologists outside the cardiac operating room $(\mathrm{OR})$ is still poorly explored. We report our experience in the use of TEE in the noncardiac OR, the recovery room and in the intensive care unit (ICU) in a university hospital, and analyze the impact of TEE on clinical decision making.

Methods: Two hundred fourteen patients were included and TEE indications were classified prospectively according to the ASA guidelines. The examinations and data sheets were reviewed by two anesthesiologists with advanced training in TEE. For each examination, it was noted if TEE altered the management according to five groups: I) changing medical therapy; 2) changing surgical therapy; 3) confirmation of a diagnosis; 4) positioning of an intravascular device; and 5) TEE used as a substitute to a pulmonary artery catheter.

Results: Eighty-nine (37\%), 67 (31\%) and 58 (27\%) patients had category I, II and III indications. The impact was more significant in category I where TEE altered therapy $60 \%$ of the time compared with $31 \%$ and $21 \%$ for categories II and III $(P<0.00 \mathrm{I})$. The most frequent reason for changing management was a modification in medical therapy in 53 instances (45\%).

Conclusion: Our results confirm a greater impact of TEE performed by anesthesiologists on clinical management for category I compared to category II and III indications in the noncardiac OR surgical setting and in the ICU.
Contexte : L'American Society of Anesthesiologists (ASA) a publié les lignes directrices pour l'utilisation périopératoire de l'échocardiographie transœesophagienne (ETO), mais le rôle et l'impact de l'ETO réalisée par les anesthésiologistes à l'extérieur de la salle d'opération (SO) sont encore peu connus. Nous présentons notre expérience de l'usage de l'ETO dans une SO non cardiaque, dans la salle de réveil et à l'unité des soins intensifs (USI) d'un hôpital universitaire. Aussi, nous analysons l'impact de l'ETO sur la prise de décision en clinique.

Méthode : Deux cent quatorze sujets ont participé à l'étude et les indications d'ETO ont été classifiées prospectivement selon les lignes directrices de l'ASA. Les examens et les fiches techniques ont été passées en revue par deux anesthésiologistes de formation avancée en ETO. Pour chaque examen, on a noté si l'ETO modifiait le traitement en regard de cinq groupes: I) modification de la thérapie médicale 2) modification de la thérapie chirurgicale 3) confirmation du diagnostic 4) installation d'une sonde intravasculaire 5) usage de l'ETO comme substitut d'un cathéter artériel pulmonaire.

Résultats : Quatre-vingt-neuf (37\%), 67 (31 \%) et 58 (27\%) patients présentaient des indications de catégorie I, II et III. L'ETO a eu un impact plus significatif pour la catégorie I où elle modifiait la thérapie dans $60 \%$ des cas comparativement à $31 \%$ et à $21 \%$ pour les catégories II et III $(P<0,00$ I). C'est la modification de la thérapie médicale qui apparaît comme la raison principale de change ment du traitement avec 53 cas (45\%).

Conclusion: Nos résultats confirment une plus grande répercussion de l'ETO réalisé par les anesthésiologistes sur le traitement clinique pour les indications de catégorie I comparées à celles de catégories II et III dans le contexte chirurgical d'une SO non cardiaque et de I'USI.

From the Department of Anesthesiology, Montreal Heart Institute; ${ }^{*}$ and the Departments of Anesthesiology $\dagger$ and Medicine, $\ddagger$ Centre Hospitalier de l'Université de Montreal (CHUM), Hôpital Notre-Dame, Montreal, Quebec, Canada.

Address correspondence to: Dr. André Y. Denault, Department of Anesthesiology, Montreal Heart Institute, 5000 Bélanger Street East,

Montreal, Quebec HIT 1C8, Canada. Phone: 514-376-3330, ext. 3732; Fax: 514-376-8784; E-mail: denault@videotron.ca Accepted for publication October 26, 2001.

Revision accepted November 16, 2001. 
I N 1996 guidelines for the use of perioperative transesophageal echocardiography (TEE) were published from a consensus conference by the American Society of Anesthesiologists and the American College of Cardiology. ${ }^{1}$ It appears from these guidelines that the impact of TEE will occur mostly during cardiac surgery. However, there is a growing interest in the use of TEE by the anesthesiologist in the noncardiac surgical setting ${ }^{2,3}$ and in the intensive care unit (ICU). ${ }^{4}$ The impact of TEE and the noncardiac procedures which are most likely to benefit from this monitoring technique are not well defined. In addition, the role of ASA guidelines for TEE has not been validated in a large number of patients in which TEE was performed in the noncardiac surgical setting.

Since the introduction of TEE in our practice in 1990 at Notre-Dame Hospital, we previously reported our experience in cardiac surgery ${ }^{5}$ but the role and impact of TEE performed solely by anesthesiologists outside of the cardiac operating theater is still poorly explored. We now are reporting our experience in the use of perioperative TEE in the noncardiac operating room (OR), the recovery room and in the ICU to determine the relative impact of category-based TEE indications.

Methods

Following approval by our Ethics Committee, all TEE examinations performed by anesthesiologists from October 1993 to February 1997 (4l months) were collected and classified in a database. Category I, II and III indications were defined according to the ASA guidelines on perioperative TEE. ${ }^{1}$ A category $\mathrm{I}$ is a condition in which the use of TEE is supported by the strongest evidence or expert opinion, a category II is associated with weaker evidence and a category III has little current scientific or expert support. TEE examinations were performed in the OR, the recovery room and the surgical ICU (SICU). Those performed in the cardiac OR were excluded. Our SICU is a mixed ICU mainly occupied by postoperative general surgery, neurosurgery and cardiac surgery patients.

TEE examinations were done using a multiplane 5$\mathrm{MHz}$ transducer (Sonos 1500, Hewlett-Packard, Andover, MA, USA) or a uniplane probe (Sonoline CF, Siemens, Pleasanton, CA, USA) and included two-dimensional imaging of the aorta, a midesophageal four-chamber and a short-axis transgastric view. The latter view was used for continuous monitoring during the procedure. A mid-esophageal twochamber and a long axis transgastric view of the left ventricle and left ventricular outflow tract were also examined when the multiplane probe was used. Color Doppler interrogation of the mitral, aortic and tricuspid valve was also performed routinely. A cardiologist trained in echocardiography (J.B.) was requested if necessary for more specific examinations such as the evaluation of unexpected severe valvular dysfunction.

At the time of examination, it was noted if TEE changed the course of the current therapy or management. This was further classified into five groups: 1) TEE findings altered medical therapy, for instance, by adding an inotrope or volume expansion; 2) TEE lead to an unplanned surgical intervention; 3) TEE confirmed or invalidated a diagnosis which could have lead to a surgical intervention; 4) TEE was useful in positioning intravascular devices; 5) TEE was used as a substitute to a pulmonary artery catheter (PAC). Nine of our anesthesiologists have basic training in TEE and two have advanced training with National Board Certification (A.D., P.C.). However, all TEE examinations and data sheets were supervised and reviewed by those with advanced training. Our interobserver variability in the evaluation of cardiac function has been published. ${ }^{6-8}$

A consensus had to be reached between the two TEE reviewers (A.D., P.C.) for an examination to be accepted as altering medical therapy, otherwise it was rejected. It was rejected if no explanation was provided or no consensus reached. TEE modified a surgical intervention only if the surgeon stated, at the time of examination, that without TEE, he would not have performed or modified his intervention. Some examinations may have been included in more than one subcategory, for instance if TEE confirmed the unsuspected presence of a patent foramen ovale during spinal neurosurgery (category III) and modified the surgical approach [lateral decubitus instead of supine position (category I)].

\section{Statistical analysis}

Chi-square analysis was used to compare the impact of TEE according to the category and group indications. Analysis of variance was used to compare age of the patients between the different groups. Statistical analysis was done using the Statview 4.1 program (Abacus Inc, Berkely, CA, USA). $P<0.05$ was considered significant.

\section{Results}

From a total of 1,065 TEE exams, $214(20 \%)$ consecutive examinations were classified as noncardiac surgery and reviewed. From these, 155 (72\%) were performed during noncardiac surgery, four $(2 \%)$ in the recovery room and $55(26 \%)$ in the SICU. Eighty- 
TABLE I Population characteristics and TEE exams

\begin{tabular}{|c|c|c|c|c|c|c|}
\hline \multicolumn{3}{|l|}{ ASA-SCA Category } & \multirow{2}{*}{$\frac{I}{89(41)}$} & \multirow{2}{*}{$\frac{I I}{67(31)}$} & \multicolumn{2}{|l|}{$I I I$} \\
\hline Total number of patients (\%) & & $n=214$ & & & $58(27)$ & ${ }^{*} \dagger$ \\
\hline Age (mean) & & 57 & 57 & 58 & 57 & \\
\hline Sex $($ male $/$ female $)$ & & $131 / 83$ & $53 / 36$ & $43 / 24$ & $35 / 23$ & \\
\hline Patients with modified therapy after TEE & & $n=86$ & 53 & 21 & 12 & ${ }^{*} \dagger$ \\
\hline Percentage per category & & & $60 \%$ & $31 \%$ & $21 \%$ & \\
\hline Age (mean) & & 60 & 61 & 60 & 52 & \\
\hline $\operatorname{Sex}($ male $/$ female $)$ & & $49 / 37$ & $32 / 21$ & $11 / 10$ & $6 / 6$ & \\
\hline Patients without modified therapy after TEE & & 128 & 36 & 46 & 46 & ${ }^{*} \dagger$ \\
\hline Percentage per category & & & $28 \%$ & $36 \%$ & $36 \%$ & \\
\hline Age (mean) & & 60 & 58 & 61 & 59 & \\
\hline $\operatorname{Sex}(\mathrm{male} /$ female $)$ & & $81 / 47$ & $19 / 17$ & $33 / 13$ & $29 / 17$ & \\
\hline \multirow[t]{3}{*}{ Site of examinations } & OR & $n=155$ & 44 & 57 & 54 & \\
\hline & $\mathrm{RR}$ & $n=4$ & 3 & 1 & & \\
\hline & SICU & $n=55$ & 42 & 9 & 4 & ${ }^{*} \dagger$ \\
\hline \multirow{3}{*}{$\begin{array}{l}\text { Number of patients with modified therapy } \\
\text { per site }\end{array}$} & OR & $n=43$ & 20 & 13 & 10 & ${ }^{*} \dagger$ \\
\hline & $\mathrm{RR}$ & $n=3$ & 2 & 1 & & \\
\hline & SICU & $n=40$ & 31 & 7 & 2 & ${ }^{*} \dagger$ \\
\hline Total number of modifications & & $n=118$ & 59 & 44 & 15 & $\dagger \ddagger$ \\
\hline
\end{tabular}

ASA $/$ SCA = American Society of Anesthesiologists/Society of Cardiovascular Anesthesiologists; TEE = transesophageal echocardiography; $\mathrm{OR}=$ operating room; $\mathrm{RR}=$ recovery room; SICU $=$ surgical intensive care unit; $\mathrm{Rx}=$ therapy. ${ }^{*} P<0.05$ for category I $v s \mathrm{II} ; \nmid P<0.05$ for category I $v$ III; $¥ P<0.05$ for category II $v s$ III.

TABLE II Summary of surgical modifications related to the use of TEE

\begin{tabular}{|c|c|}
\hline Modifications & Total number \\
\hline \multicolumn{2}{|l|}{ Hemodynamic instability in the intensive care unit } \\
\hline Tamponade leading to mediastinal exploration & 8 \\
\hline Mitral regurgitation and myocardial ischemia after gynecological & 1 \\
\hline surgery leading to mitral valve replacement and coronary revascularisation & \\
\hline \multicolumn{2}{|l|}{ Vascular surgery } \\
\hline Aortic dissection associated with pericardial effusion leading to a & 2 \\
\hline femoral bypass before surgery & \\
\hline Absence of aortic dissection & 2 \\
\hline $\begin{array}{l}\text { Unsuspected atrial thrombus and severe mitral stenosis leading } \\
\text { to thrombectomv and mitral valve replacement }\end{array}$ & 1 \\
\hline \multicolumn{2}{|l|}{ Lung transplantation } \\
\hline Right ventricular dysfunction leading to cardiopulmonary bypass & 2 \\
\hline Air emboli leading to revision of vascular anastomosis & 1 \\
\hline \multicolumn{2}{|l|}{ Neurosurgery } \\
\hline $\begin{array}{l}\text { Detection of a patent foramen ovale before ramisectomy leading } \\
\text { to surgical positional change }\end{array}$ & 2 \\
\hline Total & 19 \\
\hline
\end{tabular}

TEE $=$ transesophageal echocardiography

nine patients (37\%) had category I indications, 67 patients $(31 \%)$ had category II indications and 58 patients $(27 \%)$ were considered category III (Table I). Category I ( $n=89$ patients) were the most common indications for the use of TEE compared to category II $(P=0.027)$ and III $(P=0.0046)$.

TEE changed management in 86 patients $(40 \%)$ with a total of 118 modifications. From these 86 patients, 43 were in the OR, three in the recovery room and 40 in the ICU. Patients with changes in management were more often in category I $(60 \%)$ vs II $(31 \%)$ or III $(21 \%$; $P<0.001)$. No difference in age and sex was observed in those three categories and also in those with or without modified therapy.

In the OR, 20 patients (46\%) with modified therapy were of category I and this was more frequent than in category II $(P=0.02)$ and III $(P=0.004)$. In the SICU, 31 $(77 \%)$ patients with modified therapy were category $\mathrm{I}$. 
TABLE III Summary of studies on the impact of TEE in noncardiac surgery and in the ICU

\begin{tabular}{|c|c|c|c|c|c|c|c|}
\hline Author & Reference & $n$ & Location & Population & Overall & Medical & Surgical \\
\hline & & & & & impact & therapy & intervention \\
\hline $\mathrm{Oh}$ & 13 & 51 & $\mathrm{ICU}$ & Mixed & & & $24 \%$ \\
\hline Pearson & 14 & 62 & $\mathrm{ICU}$ & Mixed & $44 \%$ & & $8 \%$ \\
\hline Font & 10 & 112 & ICU & Mixed & & & \\
\hline Foster & 11 & 83 & ICU & Mixed & $22 \%$ & & $19 \%$ \\
\hline Reichert & 17 & 60 & SICU & Cardiac & $22 \%$ & & $3 \%$ \\
\hline Puybasset & 18 & 32 & $\mathrm{ICU}$ & Mixed & $28 \%$ & & \\
\hline Hwang & 15 & 78 & ICU ER & Mixed & $50 \%$ & & $18 \%$ \\
\hline Khoury & 19 & 77 & ICU & Mixed & $48 \%$ & $19 \%$ & $29 \%$ \\
\hline Vignon & 20 & 111 & ICU & Mixed & $36 \%$ & & $9 \%$ \\
\hline Chenzbraun & 12 & 113 & ICU & Mixed & $33 \%$ & & $16 \%$ \\
\hline Gorcsan & 21 & 48 & OR & Lung transplant & & & $25 \%$ \\
\hline Heidenreich & 22 & 61 & $\mathrm{ICU}$ & Mixed & $28 \%$ & $28 \%$ & $19 \%$ \\
\hline Sohn & 23 & 127 & ICU & $\begin{array}{l}\text { Hemodynamically } \\
\text { unstable }\end{array}$ & $52 \%$ & & $21 \%$ \\
\hline Cicek & 24 & 119 & OR and ICU & Cardiac & & & $18 \%$ \\
\hline Poelaert & 25 & 108 & ICU & No post-CABG & $44 \%$ & & $10 \%$ \\
\hline Suriani & 26 & 62 & OR & Liver transplant & $11 \%$ & & \\
\hline Alam & 16 & 121 & ICU & Mixed & $32 \%$ & & $18 \%$ \\
\hline Slama & 27 & 61 & ICU & Noncardiac & $20 \%$ & $11 \%$ & $8 \%$ \\
\hline McLean & 4 & 53 & $\mathrm{ICU}$ & Mixed & $26 \%$ & & \\
\hline Kolev & 3 & 224 & OR & $\begin{array}{l}\text { Mixed cardiac } \\
\text { and noncardiac }\end{array}$ & $30 \%$ & & \\
\hline Brandt & 9 & 66 & OR & $\begin{array}{l}\text { Mixed cardiac } \\
\text { and noncardiac }\end{array}$ & $80 \%$ & & $23 \%$ \\
\hline Suriani & 2 & 123 & OR & Noncardiac & $63 \%$ & & $15 \%$ \\
\hline
\end{tabular}

$n=$ number of examinations; $\mathrm{OR}=$ operating room; $\mathrm{ICU}=$ intensive care unit; $\mathrm{ER}=$ emergency room; CABG = coronary artery bypass graft.

Figure 1 illustrates the distribution of modifications. In 53 instances (45\%) the modification in management was secondary to a change in medical therapy. Twenty-one modifications in 19 patients (18\%) led to unplanned surgical reinterventions based on TEE findings which are detailed in Table II. Confirming or invalidating of a diagnosis was found to change management in 35 instances $(30 \%)$. The use of TEE or as a substitute to a PAC or for positioning intravascular devices was found to be useful in nine instances $(8 \%)$.

When TEE changed therapy, unplanned surgical reinterventions $(10 \%$ vs $13 \%)$ as a result of TEE were as common in category I as II but a more significant impact was found for altering medical therapy $(36 \%$ vs $21 \%)$ in category I than II $(P<0.001)$ and I vs III (36\% vs 12\%; $P<0.001$; Figure 2 ).

General, vascular and thoracic surgery represented $83 \%$ of our use of TEE in the noncardiac surgical setting. Therapy was more commonly modified in general surgery compared with vascular $(P=0.014)$ and thoracic $(P=0.043)$.
Discussion

In this study using the ASA guidelines, we observed that TEE performed by anesthesiologists can have an impact of the clinical management of patients undergoing noncardiac surgical procedures, in the recovery room and in the ICU. This was apparent mostly in category I indications. The impact of TEE in the noncardiac setting was even more important than that we had observed in cardiac surgery. ${ }^{5}$ These findings extend the role of TEE outside the cardiac surgical arena. This study represents a large anesthesiologists' experience in the use of TEE in the noncardiac surgical and in the ICU setting using the ASA guidelines. ${ }^{1}$ While TEE is most likely to be useful in category I for altering medical therapy, we did not observe any difference between categories I and II for surgical management. This could be explained by our sample size and also because, in the ASA guidelines, few situations in the noncardiac surgical setting (apart from hemodynamic instability) are associated with a category I indication. We also observed an impact of TEE in category III indications in 12 patients $(21 \%)$. This was associated with the use of TEE as a monitoring tool in 


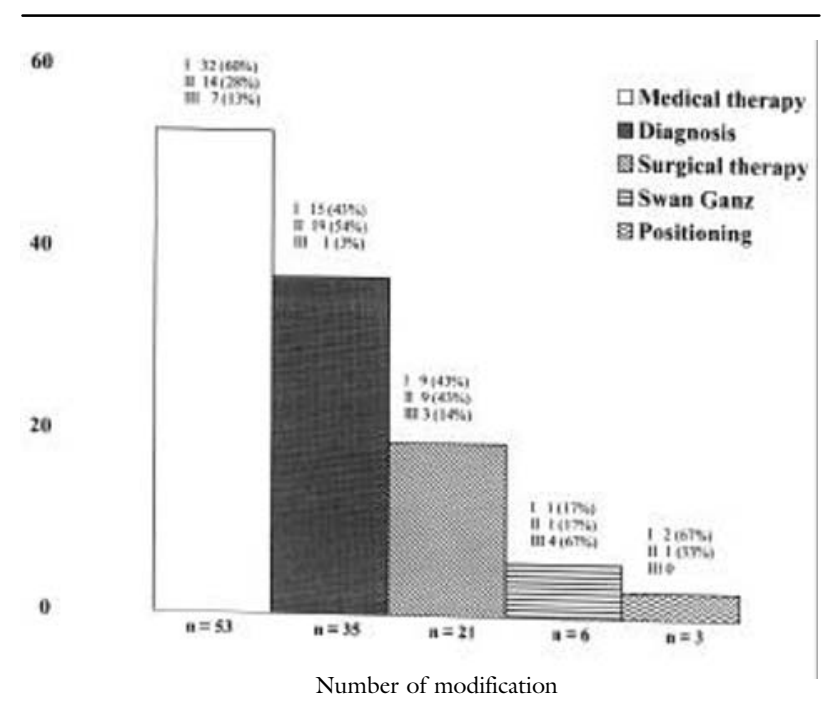

FIGURE I Distribution of the total number of modifications which are detailed according to category I through III indications for TEE.

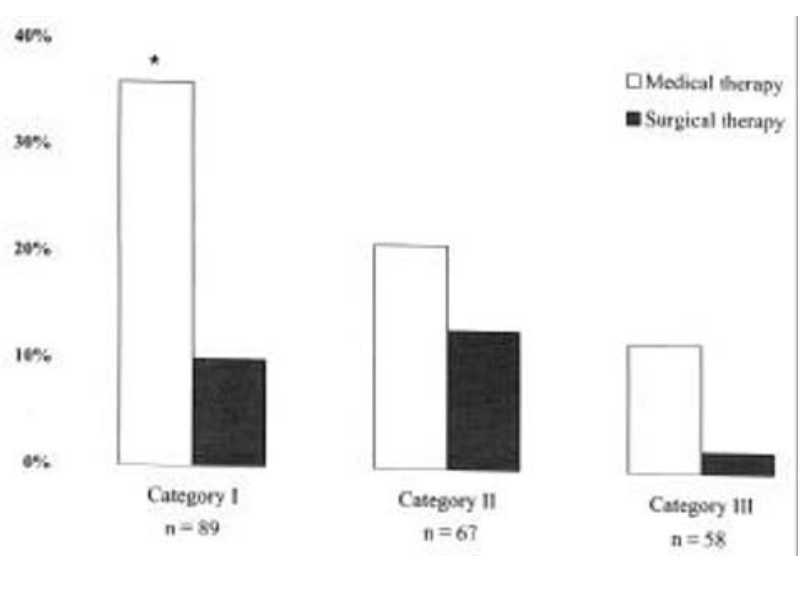

FIGURE 2 Medical and surgical impact according to indication category. $\left({ }^{*} P<0.001\right.$ for medical therapy in category I $v s$ II and I vs III; $n=$ number).

the OR and in the ICU. This group represents situations in which the role of TEE is being explored and, consequently, were classified as category III.

The only similar noncardiac study in which anesthesiologists performed TEE in the OR was reported by Suriani and coworkers ${ }^{2}$ in which the role of TEE was explored in 123 noncardiac surgery patients. They were classified as consultative if performed by a consultant or non-consultative when performed by the attending anesthesiologists. The consequences of TEE were rated as major, minor, limited and no impact. A major impact was defined as treatment of a life-threatening event, changing surgical technique or anesthetic management or leading to further evaluation in the postoperative period. Overall, the authors observed an $81 \%$ impact and a major impact was found in $15 \%$ of their patients. This is higher than our overall impact of $41 \%$ but similar to the major impact of $19 \%$ (medical and surgical) observed when considering only our noncardiac patients in the OR $(n=155)$. In agreement with Suriani's conclusions, we also found that the major advantage of TEE was its rapid diagnostic capability during the period of hemodynamic instability.

Other studies included noncardiac patients monitored with TEE in the OR. Brandt described the use of intraoperative TEE in patients undergoing cardiac $(n=46)$ and noncardiac surgery $(n=20) .{ }^{9}$ The indications in noncardiac surgery were mainly hemodynamic instability in $50 \%$. In four of these noncardiac patients undergoing vascular surgery, TEE altered the operative procedure. Kolev studied the influence of TEE on intraoperative decision making using the ASA guidelines. ${ }^{3}$ This European study included 224 patients, undergoing cardiac and noncardiac surgery, from nine participating centres. Our results are in agreement with their observations, resulting in a $30 \%$ change in overall management, with a greater impact in category I than category II.

Studies published in the ICU support our findings (Table III). The clinical experience of several authors demonstrates that TEE in the ICU picks up unexpected clinical findings in $25 \%$ to $59 \%$ of patients and has a direct influence on the therapeutic decisions in $8 \%$ to $24 \%$ of cases. ${ }^{10-16}$ However, anesthesiologists trained in TEE were not reported as those performing the echocardiographic examination in most of these studies.

\section{Limitations}

The greater impact of TEE in noncardiac surgery compared to cardiac surgery can be explained by the nonroutine use of TEE in these patients. Consequently, a bias could be introduced as patients are selected because they are more likely to benefit from TEE. Using routine TEE for noncardiac surgery would have yielded a lower impact but this does not represent our practice. In the noncardiac surgery setting, we use TEE mostly in category I indications, and this supports that the use of TEE in this context has a significant impact. Similarly, the role of TEE in the ICU is clearly established during critical situations. We did not exclude postoperative cardiac surgery patients because of our mixed ICU population. However, this could have reduced the overall surgical impact in the ICU. We strongly believe that TEE has the 
potential to become an essential tool for noncardiac anesthesiologists in unstable patients undergoing noncardiac surgery and in the ICU because of its rapid diagnostic capabilities. This advantage of the TEE has to be weighed against the cost and size of the equipment and the expertise required at the bedside for continuous monitoring. At present, this type of monitoring is available mostly in the cardiac operating suites of large centres. Certification by the National Board of Echocardiography is now available for perioperative TEE and may become mandatory for anesthesiologists eager to make use of this diagnostic and monitoring modality.

In summary, TEE performed by anesthesiologists can have a significant impact in the non-cardiac surgical theater, in the recovery room and the ICU. TEE utilization has a greater impact for category I than categories II or III of the ASA indications and results mainly in modifications of medical therapy.

\section{Acknowledgements}

This study was supported by the "Plan de Pratiques des anesthésiologistes de l'Hôpital Notre-Dame du CHUM et de l'Institut de Cardiologie de Montréal, the "Bourse Sheridan de la Société canadienne d'anesthésiologie" and the "Fondation d'anesthésiologie du Québec de l'Association des anesthésistes du Québec". We thank Luce Bégin for secretarial support.

\section{References}

1 American Society of Anesthesiologists and the Society of Cardiovascular Anesthesiologists Task Force on Transesophageal Echocardiography. Practice guidelines for perioperative transesophageal echocardiography. A report by the American Society of Anesthesiologists and the Society of Cardiovascular Anesthesiologists Task Force on Transesophageal Echocardiography. Anesthesiology 1996; 84: 986-1006.

2 Suriani RJ, Neustein S, Shore-Lesserson L, Konstadt S. Intraoperative transesophageal echocardiography during noncardiac surgery. J Cardiothorac Vasc Anesth 1998; 12: 274-80.

3 Kolev N, Brase R, Swanevelder J, et al. The influence of transoesophageal echocardiography on intra- operative decision making. A European multicentre study. European Perioperative TOE Research Group. Anaesthesia 1998; 53: 767-73.

4 McLean AS. Transoesophageal echocardiography in the intensive care unit. Anaesth Intensive Care 1998; 26: 22-5.

5 Couture P, Denault AY, McKenty S, et al. Impact of routine use of intraoperative transesophageal echocardiography during cardiac surgery. Can J Anesth 2000; 47: $20-6$
6 Bernard F, Denault A, Babin D, et al. Diastolic dysfunction is predictive of difficult weaning from cardiopulmonary bypass. Anesth Analg 2001; 92: 291-8.

7 Couture P, Denault AY, Carignan S, Boudreault D, Babin D, Ruel M. Intraoperative detection of segmental wall motion abnormalities with transesophageal echocardiography. Can J Anesth 1999; 46: 827-31.

8 Girard F, Couture P, Boudreault D, Normandin L, Denault A, Girard D. Estimation of the pulmonary capillary wedge pressure from transesophageal pulsed Doppler echocardiography of pulmonary venous flow: influence of the respiratory cycle during mechanical ventilation. J Cardiothorac Vasc Anesth 1998; 12: 16-21.

9 Brandt RR, Ob JK, Abel MD, Click RL, Orszulak TA, Seward JB. Role of emergency intraoperative transesophageal echocardiography. J Am Soc Echocardiogr 1998; 11: 972-7.

10 Font VE, Obarski TP, Klein AL, et al. Transesophageal echocardiography in the critical care unit. Cleve Clin J Med 1991; 58: 315-22.

11 Foster E, Schiller NB. The role of transesophageal echocardiography in critical care: UCSF experience. J Am Soc Echocardiogr 1992; 5: 368-74.

12 Chenzbraun A, Pinto FJ, Schnittger I. Transesophageal echocardiography in the intensive care unit: impact on diagnosis and decision-making. Clin Cardiol 1994; 17: $438-44$.

13 Oh JK, Seward JB, Khandheria BK, et al. Transesophageal echocardiography in critically ill patients. Am J Cardiol 1990; 66: 1492-5.

14 Pearson AC, Castello R, Labovitz AJ. Safety and utility of transesophageal echocardiography in the critically ill patient. Am Heart J 1990; 119: 1083-9.

15 Hwang JJ, Shyu KG, Chen JJ, Tseng YZ, Kuan P, Lien $W P$. Usefulness of transesophageal echocardiography in the treatment of critically ill patients. Chest 1993; 104: 861-6.

16 Alam M. Transesophageal echocardiography in critical care units: Henry Ford Hospital experience and review of the literature. Prog Cardiovasc Dis 1996; 38 : $315-28$.

17 Reichert CL, Visser CA, Koolen JJ, et al. Transesophageal echocardiography in hypotensive patients after cardiac operations. Comparison with hemodynamic parameters. J Thorac Cardiovasc Surg 1992; 104: 321-6.

18 Puybasset L, Saada M, Catoire P, Bonnet F. Contribution of transesophageal echocardiography in intensive care: a prospective assessment (French). Ann Fr Anesth Réanim 1993; 12: 17-21.

19 Khoury AF, Afridi I, Quinones MA, Zoghbi WA. Transesophageal echocardiography in critically ill 
patients: feasibility, safety, and impact on management. Am Heart J 1994; 127: 1363-71.

20 Vignon P, Mentec H, Terre S, Gastinne H, Gueret P, Lemaire F. Diagnostic accuracy and therapeutic impact of transthoracic and transesophageal echocardiography in mechanically ventilated patients in the ICU. Chest 1994; 106: 1829-34.

21 Gorcsan J 3rd, Edwards TD, Ziady GM, Katz WE, Griffith BP. Transesophageal echocardiography to evaluate patients with severe pulmonary hypertension for lung transplantation. Ann Thorac Surg 1995; 59:

717-22.

22 Heidenreich PA, Stainback RF, Redberg RF, Schiller NB, Cohen NH, Foster E. Transesophageal echocardiography predicts mortality in critically ill patients with unexplained hypotension. J Am Coll Cardiol 1995; 26: 152-8.

23 Sobn DW, Shin GJ, Oh JK, et al. Role of transesophageal echocardiography in hemodynamically unstable patients. Mayo Clin Proc 1995; 70: 925-31.

24 Cicek S, Demirilic U, Kuralay E, Tatar H, Ozturk O. Transesophageal echocardiography in cardiac surgical emergencies. J Card Surg 1995; 10: 236-44.

25 Poelaert JI, Trouerbach J, De Buyzere M, Everaert J, Colardyn FA. Evaluation of transesophageal echocardiography as a diagnostic and therapeutic aid in a critical care setting. Chest 1995; 107: 774-9.

26 Suriani RJ, Cutrone A, Feierman D, Konstadt S. Intraoperative transesophageal echocardiography during liver transplantation. J Cardiothorac Vasc Anesth 1996; 10: 699-707.

27 Slama MA, Novara A, Van de Putte P, et al. Diagnostic and therapeutic implications of transesophageal echocardiography in medical ICU patients with unexplained shock, hypoxemia, or suspected endocarditis. Intensive Care Med 1996; 22: 916-22. 